\title{
Investigating the effects of polymer plugging mechanism of liquid production decrease and improvement by the crosslinked gel performance
}

\author{
MAHAMAT TAHIR ABDRAMANE MAHAMAT ZENE ${ }^{1,2}$,LI BAOZHEN ${ }^{1}$,Ruizhong Jiang ${ }^{1,2}$, \\ Haijun Fan ${ }^{2}$, Yongzheng Cui ${ }^{2}$, Liu Xiu Wei ${ }^{2}$ \\ ${ }^{1}$ State Key Laboratory of Offshore Oil Exploitation, Beijing 100028, China \\ ${ }^{2}$ China University of Petroleum (East China) Qingdao, 266580, Shandong Province, China \\ Corresponding Author: Ruizhong Jiang (jrzhong@126.com)
}

This research was funded by the State Key Laboratory of Offshore Exploitation (CCL2018RCPS0036RON) and supported by the Fund of Southern Marine Science and Engineering Guangdong Laboratory (Zhanjiang) grant (ZJW-2019-04).

ABSTRACT: Polymer flooding, as the most successful and well-known chemical EOR method which is broadly applied around the world. Mostly, contrasted with Waterflooding, the production rate decrease during polymer flooding is smaller based on field application. But, the production liquid rate decreased critically in the middle phase to late phase due to plugging, which could lead the way to poor flooding performance and fewer cumulative oil. In this work, first we approached the affecting polymer plugging mechanism model on liquid production decrease to investigate the parameters such as; solid phase concentration (SOLIDMIN), reacting frequency factor (FREQFAC) and others affecting components are all investigated consecutively. Secondly the model approached by crosslinked gel for the improvement of production liquid rate. The work physical model was designed through a physical model, and then the polymer adsorption which causing blockage resulting in permeability decrease computed by mathematical model. The results indicate that the presence of this debris, high concentration of solid phase and the high reactant frequency factor has major mechanical and physical parameters effects on the reservoir during polymer flooding. Polymer flood model investigated under crosslinked gel model performed reliable results by removing the plugging which caused the reservoir production rate to decrease. Future work has to be concentrated more on understanding and improving the parameters of (SOLIDMIN) and (FREQFAC) for the enhancement of reservoir performance.

INDEX TERMS: Crosslinked gel performance, plugging mechanism, polymer flooding, liquid production decrease, plugging removal

\section{INTRODUCTION}

Reduction in formation permeability or hydraulic conductivity has attracted much concern in the oilfield development stage;[1]. The loss of permeability and poor hydraulic conductivity usually lead to serious heterogeneity and low fluid production, and thus effect oil production. It is commonly referred to as formation damage in an oilfield.

Generally, solid-phase invasion, fines migration, scale formation, and water sensitivity [2] can cause pollution and plugging near the wellbore which has adverse effects on oil production.

Acidizing treatment is one of the most important techniques that has been utilized in attempting to remove the pollution and recover formation permeability [3].

Typical synthetic polymers are partially hydrolyzed polyacrylamide (HPAM) and its derivatives. HPAM have been used for large-scale production in many fields because it is less costly [4].

Other polyacrylamide-derived polymers used in EOR include hydrophobically associating polymers, salinity tolerant polyacrylamide (KYPAM), and 2acrylamide 2-methyl propane sulfonate (AMPS) [5]. Application of biopolymers like xanthan gum and cellulose for EOR has been demonstrated in few fields[6]. Biopolymer not only lowers the water to oil mobility ratio but also selectively plugs the highpermeability thief zones and leads to a redirection of the water-flood to inaccessible oil zones[7].

Laboratory results showed that this selective plugging is due to the action of resident bacteria which can feed either on hydrocarbons or on biopolymer such as xanthan gum[7, 8]. Additionally, polymer gels, polymer-enhanced foams, and foamed gels have also 
been used to improve oil recovery by plugging the high permeability thief zones [9].

Water production in oil-producing wells becomes more and more serious as the wells mature, and it is very important to control water production and improve oil recovery[10, 11]. Among many profile control techniques, in-depth profile control methods have been developed quickly and practiced successfully such as cross-linked polymer microspheres[10, 12] and delayed crosslinking polymer gel, which is widely used because of its high gel strength and good plugging effect [13, 14, 15]. There are two main issues that need further attention in the application of delayed crosslinking polymer gel systems: the gelation time and the gel strength.

The gelation time determines the extent of gel penetration into formation layers when polymer gel system is injected, while the salt resistance and temperature resistance performance of the polymer determine the gel strength of the gels system.

Adjustable gelation time is necessary in delayed crosslinking polymer gels systems during the profile control process $[13,15,16]$.

There are many ways to control the gelation time and the key is to control the release rate of the crosslinkers. The most commonly used polymer gel systems in profile control are hydrolyzed polyacrylamide (HPAM) and chromium (III) ions[17].

Gels prepared with metallic crosslinkers such as chromium chromium, aluminum, and zirconium have lower stability at high temperature and short gelation time, and are not profitable in high temperature reservoirs and deep profile control process. The crosslinking ions can be formed into chelated ions to increase the gelation time, but there are limitations to the gelation strategy due to the lack of control over the release kinetics of chelated crosslinking ions. Another popular water-based gel system for water-control applications is based on a phenol/formaldehyde crosslinker system [15, 17, 18]. The phenol/formaldehyde polymer gel system is thermally stable, and the gelation time is controllable over a wide temperature range [15]. Multiple emulsions can also be employed to increase the gelation time for the delayed crosslinking polymer gel systems [19].

The most commonly used polymer in the polymer gel systems for water shut-off is hydrolyzed polyacrylamide (HPAM). The viscosity enhancement of HPAM is mainly up to the expansion of solvated chains, owing to the repulsion of carboxylate groups. HPAM shows poor salt resistance, temperature resistance, and shear resistance performance, which hindered its application in high temperature and high salinity reservoirs [20].

As a result, many polymers are developed and applied in high temperature and high salinity reservoirs, such as modified xanthan, amphiphilic polymer like hydrophobically modified polyacrylamides (HMPAM), and so on. For example, the modified xanthan/chromium gels are stable up to at least $120^{\circ} \mathrm{C}$ [21].

Compared with HPAM, HMPAM exhibits much better salt resistance, temperature resistance, and shear resistance performances; much higher thickening property; and good emulsification performance, and thus can enlarge both the swept volume and displacement efficiency $[22,23]$.

In the Cartesian coordinate as the size of the well block increases, velocity smears, and thus shear rate and consequently polymer viscosity is erroneously calculated [24].

The physical adsorption of polymer is modeled with Langmuir isotherm equation. Polymer adsorption can reduce the effective permeability [25].

The permeability reduction is measured by a permeability reduction factor $\left(R_{k}\right)$ which is the ratio of effective permeability to brine and polymer solution. The effect of permeability reduction is assumed to be irreversible and lasts after polymer flooding and is called residual resistance factor $\left(\mathrm{R}_{\mathrm{RF}}\right) \mathrm{R}_{\mathrm{RF}}$ is defined as the ratio of the mobility of a brine solution before and after the polymer injection. The permeability reduction factor is not significant for many polymers such as Xanthan gum or when the formation permeability is high [26].

The injectivity decrease due to the permeability reduction factor ceases when polymer retention reaches its maximum level.

During the operation of water plugging, one of the most common failure phenomena is that the polymer gel is easily penetrated by the subsequent water flow due to the defection of the polymer material.

Thus, a new water channel is formed and the expansion of the swept volume is limited [27]. This is because plugging the fracture requires a polymer gel with a continuous body and a high mechanical strength, which can fully plug the water channel and maintain a good performance under the long-term washing of the injected water.

Based on the field statistics of the Changqing oilfield and Yanchang oilfield, the most applied polymer gels are the gel particles and the in-situ cross-linking polymer gel. Gel particles have a dense threedimensional network structure with a strong energy storage capacity, a high strength, and high viscoelasticity [28].

The objective of this research is to investigate the the main parameters causing plugging mechanism on the reservoir production rate. and applying crosslinked gel for improving the affected parameters and boosting the production rate. 
The influencing parameters are evaluated by $\mathrm{CMG}$ STARS software. This research presents a transparent approach for upcoming research.

The advanced process simulators STARS is a fully featured thermal compositional model (Rubin and Buchanan, Oballa et al) that has been applied in a broad type of primary recovery and secondary recovery simulation for more years. Furthermore, to it is norm reservoir gridding abilities, fully coupled well models, and advanced numerical solution techniques including adaptive implicit algorithms, its flexibility in

\section{Computational methodology}

This research work is based on a 5 spot-pattern model of $21 \times 21 \times 5$ grid blocks in total 2205 are active was been modeled for the realization of this study. $\mathrm{X}$ and $\mathrm{Y}$ with grid dimensions of $40 \mathrm{ft}$. It is divided into 5 layers from top to bottom. That means the average describing various fluid flow process and mechanisms is particularly noteworthy. These final stage abilities include consist of the effects of process additives as following; polymer, gels, surfactants, and foams [29] .

Therefore, the common multi-component multiphase non-equilibrium initially established for insitu combustion modeling it is applied to portray other non-equilibrium mixing and phase change process such as foamy oils [30]. The effectiveness of this kind of ability in the modeling of sand movement as well as production will be expanded in this work.

thickness of a 1 layer is $5 \mathrm{ft}$. Water Oil Contact (WOC) is $4050 \mathrm{~m}$ and the Gas Oil Contact (GOC) is $4000 \mathrm{~m}$.

The permeability varies from the 1 st layer to the 5 th layer $(X, Y$, and $\mathrm{Z}$ ), direction as stated in TABLE I and (fig. 1.).

TABLE I

Base case model description and physical properties of the test scenarios

\begin{tabular}{|c|c|c|}
\hline Parameter description & Units & Values \\
\hline Cell in X direction(DX) & $\mathrm{X}$ grid block sizes, $\mathrm{ft}$. & 21 \\
\hline Cell in Y direction(DY) & $\mathrm{Y}$ grid block sizes, ft. & 21 \\
\hline Cell in $\mathrm{Z}$ direction(DZ) & Z grid block sizes, $\mathrm{ft}$. & 5 \\
\hline Total cell number & Total cell of the block, ft. & 2205 \\
\hline Porosity & Grid block porosity values, $\%$ & 0.23 \\
\hline Permeability in $\mathrm{X}$ direction & Permeability in $\mathrm{X}$ direction, $\mathrm{mD}$ & $500,1000,1600,1050,1700$ \\
\hline Permeability in $\mathrm{Y}$ direction & Permeability in $\mathrm{Y}$ direction, $\mathrm{mD}$ & $500,1000,1600,1050,1700$ \\
\hline Permeability in $\mathrm{Z}$ direction & Permeability in $\mathrm{Z}$ direction, $\mathrm{mD}$ & $50,100,160,105,170$ \\
\hline Water mobility weight & Water MW kg/gmole & 18.02 \\
\hline Polymer & Polymer MW kg/gmole & 8 \\
\hline Dead oil & Dead oil MW kg/gmole & 1 \\
\hline Sand & Sand MW kg/gmole & 1.25 \\
\hline N_moving sand & Nonmoving sand MW & 1.25 \\
\hline Reference pressure & Reference pressure, $\mathrm{kPa}$ & 18000 \\
\hline Water density & Water density $\mathrm{kg} / \mathrm{m}^{3}$ & 1061.99 \\
\hline Polymer & Polymer density $\mathrm{kg} / \mathrm{m}^{3}$ & 794.4 \\
\hline Dead oil & Dead oil $\mathrm{kg} / \mathrm{m}^{3}$ & 954.999 \\
\hline Sand & Sand density $\mathrm{kg} / \mathrm{m}^{3}$ & 2650 \\
\hline N_moving sand & N_moving sand $\mathrm{kg} / \mathrm{m}^{3}$ & 2650 \\
\hline Water liquid compressibility & Water liquid compressibility, $\mathrm{kPa}$ & $3.3 \mathrm{e}-6$ \\
\hline Polymer liquid compressibility & liquid compressibility, $\mathrm{kPa}$ & $3.3 \mathrm{e}-6$ \\
\hline Dead oil liquid compressibility & liquid compressibility, $\mathrm{kPa}$ & $8.96 \mathrm{e}-6$ \\
\hline Sand liquid compressibility & liquid compressibility, $\mathrm{kPa}$ & $1 e-007$ \\
\hline N_moving sand liquid compressibility & liquid compressibility, $\mathrm{kPa}$ & $1 e-007$ \\
\hline Water compressibility & Water compressibility ,Psia & 0.000725189 \\
\hline Polymer injection & $\mathrm{Wt} \% \mathrm{PV}$ & 1.75 \\
\hline Dead Pore volume & Dead Pore, PV & 0.15 \\
\hline Residual Resistance Factor & Residual Resistance Factor (RRF) & 1.5 \\
\hline Initial water saturation & Initial water saturation, $\%$ & 0.5 \\
\hline Reference temperature & Temperature, $\mathrm{C}$ & 60 \\
\hline Connate water saturation & Connate water saturation, $\%$ & 0.2 \\
\hline
\end{tabular}




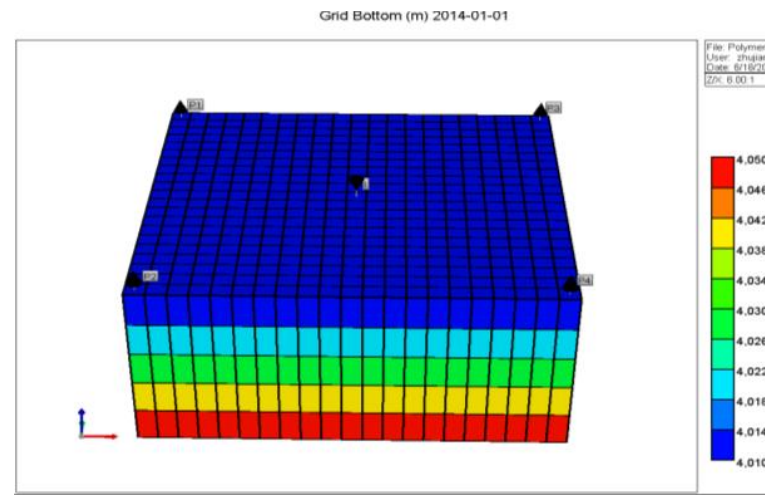

Fig. 1. 3D model of inverted five (5) spot pattern polymer flooding model.

The reservoir water injection well is fixed on constraint STW surface water rate of $100 \mathrm{~m}^{3} /$ day, with a BHP operated at $17000 \mathrm{kPa}$ on maximum. Whereas the producer wells are fixed to operate on BHP (bottom hole pressure) of $16000 \mathrm{kPa}$. The liquid phase viscosity table varies from $25^{\circ} \mathrm{C}$ minimum to a maximum of $100^{\circ} \mathrm{C}$.
The non-equilibrium blockage mechanism operated with the SOLIDMIN and the FREQFACT with differing range for the base cases (polymer flood model and crosslinked gel model) beside the sensitivity cases in TABLE II

TABLE II

List of test cases for the established study of the polymer model and crosslinked gel model

\begin{tabular}{lll}
\hline \hline Parameter description & Units & Values \\
& & \\
\hline Base case & 0.0052 & 0.031 \\
Base case & 0.0052 & 0.031 \\
Case 1 & 0.023 & 0.002312 \\
Case 2 & 0.023 & 0.000002 \\
\hline
\end{tabular}

For the achievement of this work, CMG STARS software is used [31] as described in more details in Fig.2. Workflow and software usage considered, then the key components with descriptions models of Fig. 3 and fig. 4.

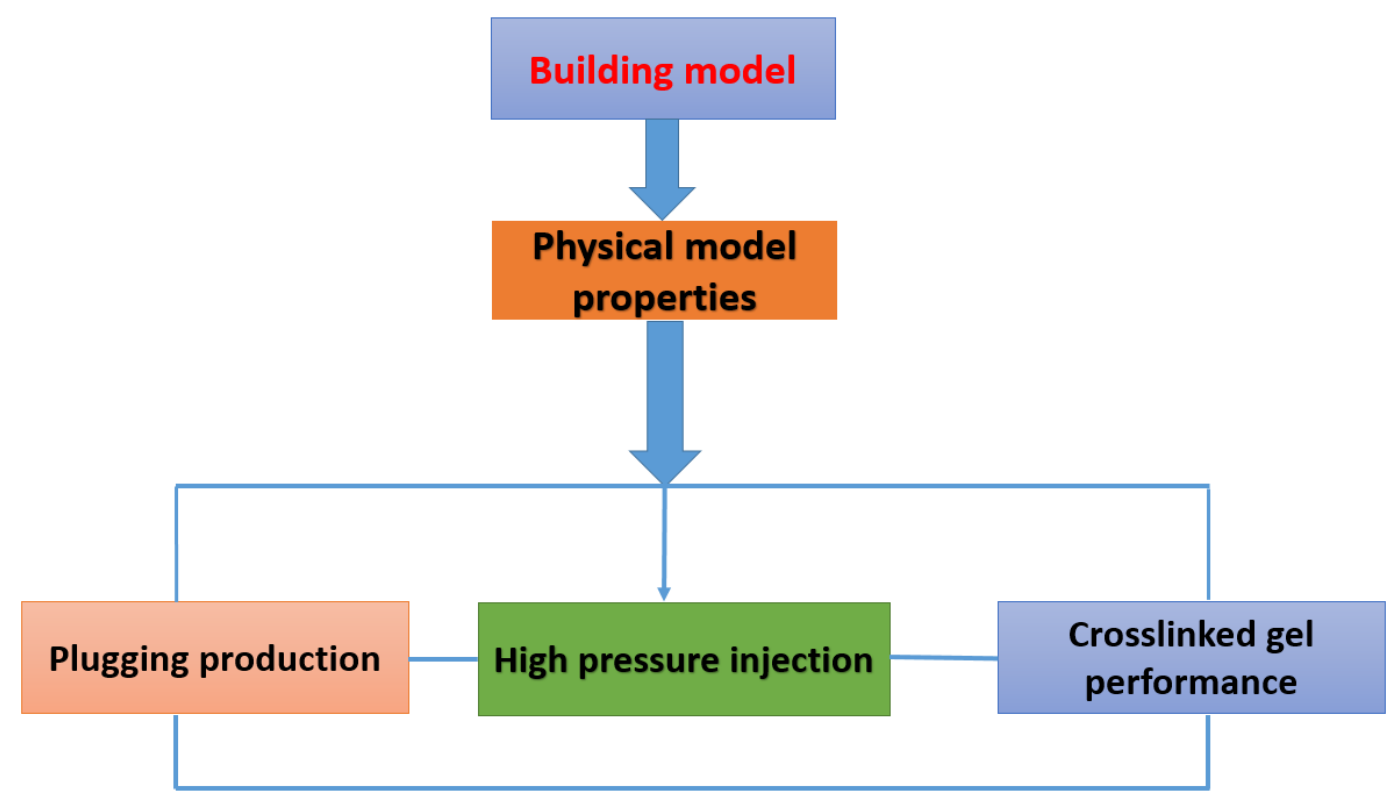

Fig. 2. Workflow and software usage 


\section{* Component name* \\ 'N_MOVING'(solid phase) and SAND which is present in the oil phase (oleic)}

*STOREACT indicate (coefficient of the reacting component), *STOPROD (coefficient of the producing component), *FREQFAC indicate( the reacting frequency factor),reacting component are defined: SAND and 'N_MOVING'

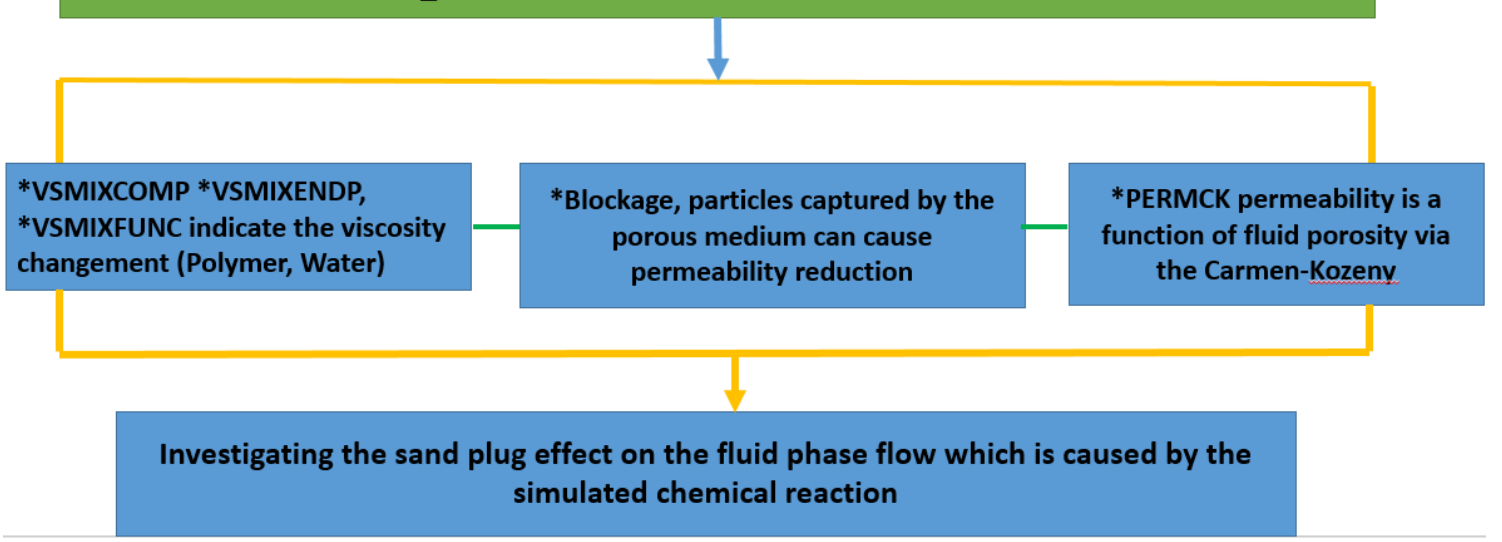

Fig. 3. Keyword description of Polymer sand plug model

*Component name*

Crosslinker, gel are determined in the (aqueous phase), and Xanthan which is determined in the (solid phase)

*STOREACT indicate (coefficient of the reacting component), ${ }^{*}$ STOPROD (coefficient of the producing component), *FREQFAC indicate( the reacting frequency factor),reacting component are defined crosslinked gel is considered

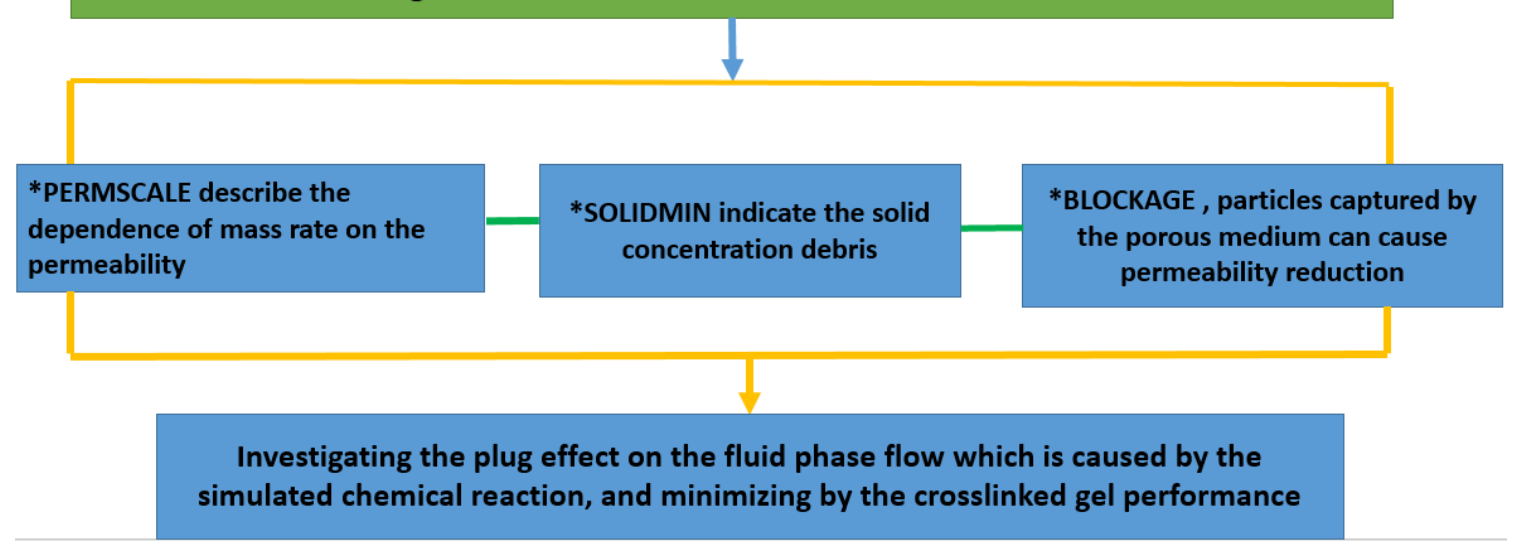

Fig. 3. Keywords description of the crosslinked gel reaction model

During the application of polymer flooding model, the sand movement and circulation treatment are approached as follow in this work:

'N_MOVING': the sand component that is in the solid phase which is non mobile or non-moving
(Solid). The non-mobile sand can cause permeability reductions (blockage) like to equilibrium mass transfer to the rock (Adsorption).

SAND: The sand component that is present in the oil phase (oleic), it is carried into oil and released 
whereas the gateway formation operating. The existence of this component can change the viscosity of the oil, in substance influencing the movement of sand toward the producer well extremity.

('N_MOVING') is the Initial solid concentration which is manually defined with a concentration of 0.052 and the oil mole fraction (sand) of 0.0025 also defined manually and both are computed by the software.

(STOREACT); The effect of reaction frequency activation energy which is present into the reaction in the component of CMG STARS (STARS USER GUIDE), indicates the frequency factor of the reacting component. It plays a major role in the results as well as the plugging influences. In a model component, it is known that the chemical component is in the stoichiometric ratios, each concentration defined by it is weight during the sand plug model (polymer, Sand, 'N_MOVING') reaction result in sand solid concentration.

To define the best molecular weight of the polymer, it is useful to consider reservoir permeability and oil viscosity.

The gel is broadly used around the world for it is conformance control, by injecting gel concentration, decrease the permeability of high zone which is blocked or plugged without affecting the less permeable zone. That means more oil could be recovered from the non-swept less permeable zone. The basic modeling approach follows [32].

The fluid data model was described with 6 chemical components: water, polymer (polyacrylamide), crosslinker (phenolformaldehyde) and gel defined in the aqueous phase, dead oil, and solution gas defining the oleic phase. The polymer and gel components also adsorbed on the rock.

Polymers can be also classified as biopolymers (natural polymers) and synthetic (plastic) polymers.

Natural polymers are produced by microscopic organisms such as bacteria, fungus whereas synthetic polymers are synthesized by scientists (or humans) [33].

With the injection of the polymer into the formation, enfolded into the extinct dimension. Below some of the following conditions: high temperature, and high pressure, the plugging with complicated mechanisms is formed.

For the blockage or plugging treatment, a model data composed of the following chemical components: Water, polymer, crosslinker, gel are determined in the aqueous phase, xanthan (solid phase) and dead oil (Oleic phase).

The polymer, gel and xanthan components are absorbed into the rock. Polymer, xanthan, and crosslinked gel are applied for: porosity, permeability, water viscosity, polymer degradation, inaccessible pore volume, the high concentration of solid phase and the high reactant frequency factor.

Xanthan is resistant to mechanical degradation (shear), and is thermally stable in the temperature range from 70 , to $90^{\circ} \mathrm{C}$ [34] .

Nonetheless, this compound is very sensitive to bacterial degradation when injected into the field containing low-temperature regions in the reservoir. Furthermore, it has been reported that xanthan can have some cellular debris that causes plugging [35].

In the current research work, some of the following polymers are considered; Hydrolyzed Polyacrylamide (HPAM), biopolymers (xanthan) and synthetic polymer as a gel.

HPAM is a polyelectrolyte which interacts strongly with ions in solution. The flexibility of HPAM polymeric chain structure makes it more interactive to the ionic strength of aqueous solutions and hence more sensitive to salt/hardness compared to other polymers such as xanthan gum [36].

Xanthan gum is a biopolymer released by the microorganism Xanthomonas campestris and is manufactured commercially by the fermentation process. Aqueous solutions of xanthan gum are highly viscous owing to the existence of double and triple helix structure of the polymer chain with larger polar side chains that promote extensive hydrogen bonds [37].

Gel injection is one of the most efficient technique of EOR to increase oil recovery. Especially in heterogeneous reservoirs, gel injection could be preferred rather than polymer injection [38].

The idea of using gels for oil recovery has started in the 1990s.

Biopolymers and synthetic polymers which form gelation, thickening or emulsification/stabilizing agents have been used successfully in the oil reservoirs [23]. With the commercially available 
biopolymers and synthetic polymers in aqueous solutions, this mixture produces gels as a result of thickening of water [39]. The movable gels have high viscosity that leads increase of oil mobility. Gels have been used in highly permeable reservoirs to reduce permeability. Hydrogels or water based gels decrease the permeability of water rather than oil permeability [40].

Similarly, oil based gels reduce the permeability of oil compared to water permeability. Resistance factor increases due to high viscosity of water and low permeability that shows increment of recovered oil [41].

Microgels, performed particle gel (PPG), $\mathrm{pH}$ sensitive crosslinked polymers are the commercially available gels to use in the petroleum reservoirs.

The interaction between gels and water can make the gels shrink, swell or stay in the same size based on the gel type, salinity of water, temperature and shear rate [42]. PPG is costeffective and environment friendly and it is not sensitive to water salinity and minerals. The size of PPG can be controlled based on the pore sizes to decrease permeability. Gels have been applied to heterogeneous reservoirs to make the reservoirs homogenous [43]. Therefore, gels injection can also be preferred due to its increment of sweep efficiency before injecting an expensive polymer. The blockage mechanism was used for the distinct cases of polymer model and the gel crosslinked are investigated under the identical model.

The permeability reduction is due to mechanical entrapment and it illustrated as phase permeability reduction [44].

The permeability which is effected or changing during polymer flooding and crosslinked gel model cannot be viewed in the $3 \mathrm{D}$ model result.

The permeability reduction is dependent on the adsorption data component by ADSCOMP. The rock dependent adsorption is described as following: (see the nomenclature)

This change before polymer flooding and after polymer flooding can be computed through the equation (1) below:

$$
\bar{K}=\frac{K_{b p}}{R_{K}}
$$

The adsorption component defined as the adsorption component, residual resistance factor, and desorption level relies on the permeability of the formation.

Reservoir heterogeneities can cause these properties to change considerably within a reservoir. Therefore, equilibrium adsorption is a function of location as well as component concentration and temperature.

The adsorption can cause the blockage which is the decreased quantity in the effective permeability. This is regarded as for scaling the adsorption obtained from local concentration and temperature conditions by the factor [45].

$$
\begin{aligned}
& R_{K W}=\frac{1+(R R F-1) \times A D(C, T)}{A D M A X T} \\
& R_{K o}=\frac{1+(R R F-1) \times A D(C, T)}{A D M A X T}
\end{aligned}
$$

As the quantity of adsorption level increase in function of time, $R_{k}$ change from 1.0 to it is highest $R R F$. Before the application of polymer flooding the RRF with mobility variation can be stated as follows:

$$
R R F=\frac{\lambda_{W b}}{\lambda_{W a}}=\frac{K_{w b}}{K_{w a}} \frac{\mu_{w b}}{\mu_{w a}}
$$

Polymer flooding decreases the permeability of each layer, mainly depending on the solid concentration phase of the polymer adsorption, which in return decreases the permeability of each layer. A linear fluid flow by Darcy law will be applied as following; considering an invariant flow rate and total pressure decrease $\Delta_{p}$ is the total of the decrease of each layer.

$$
K=\frac{Q \times L \times \mu}{A \times \Delta_{p}}
$$

Where, $\quad \Delta_{p}=\Delta_{p 1}+\Delta_{p 2}+\Delta_{p 3} \ldots \ldots \Delta_{p n}$

Replacing the pressure decrease by Darcy equation for every 5 layers and permeability:

$$
\frac{q \mu L a}{A k_{a}}=\frac{q \mu L a_{1}}{A k_{1}}+\frac{q \mu L a_{2}}{A k_{2}}+\frac{q \mu L a_{3}}{A k_{3}}+\frac{q \mu L a_{4}}{A k_{4}}+\frac{q \mu L a_{5}}{A k_{5}}
$$


Eliminating the same terms and clarifying the equation will become as:

$$
K_{a}=\frac{L e}{\left(\frac{L a}{k}\right) 1+\left(\frac{L a}{k}\right) 2+\left(\frac{L a}{k}\right) 3+\left(\frac{L a}{k}\right) 4+\left(\frac{L a}{k}\right) 5}
$$

$$
K_{a}=\frac{\sum_{e=1}^{n} L_{e}}{\sum_{e=1}^{n}\left(L_{a} / \mathrm{k}\right)_{e}}
$$

Where, AK defined as standard grid block permeability for water as $A K_{w}(\mathrm{i}, \mathrm{j}, \mathrm{k})$ issue and for oil as $A K_{o}(\mathrm{i}, \mathrm{j}, \mathrm{k})$. The relative mobility of the phase holding an absorbing component is surely affected by the viscosity and blockage.

Where, $(i, j, k)$ indicate the grid block permeability flow in different direction.

The permeability reduction affects the permeability of water and oil are stated as following; $A K_{w}(\mathrm{i}, \mathrm{j}, \mathrm{k}), A K_{o}(\mathrm{i}, \mathrm{j}, k)$ as:

$$
A K_{w}(\mathrm{I})=\frac{\mathrm{AK}(\mathrm{i}, \mathrm{j}, \mathrm{k}) \times K_{R W}}{R_{K W}(\mathrm{i}, \mathrm{j}, \mathrm{k})}
$$

$$
A K_{o}(\mathrm{i}, \mathrm{j}, \mathrm{k})=\frac{\mathrm{AK}(\mathrm{i}, \mathrm{j}, \mathrm{k}) \times K_{R O}}{R_{K O}(\mathrm{i}, \mathrm{j}, \mathrm{k})}
$$

Polymer adsorption which results in permeability decrease estimated by the factor as follows:

$$
R_{K}=\frac{K_{w}}{K_{p o}}
$$

The non-accessible pore volume (IPV) first was proposed by (Daws on and Lauthz 1972), that some pore are not reached during the polymer and it was finally confirmed by (Pancharoen Thiele and Kovscek 2010), the effective polymer porosity is less than the actual. The following pore volume method realizable by the aqueous polymer solutions:

$$
\phi_{p}=(1-I P V) \times \phi
$$

\section{Results and discussion}

\section{A. Test cases and justification}

1) BASE CASE: POLYMER SAND PLUG MODEL

Sand plugging occurring investigated toward the production well into; 1D model as well compared with the graph figures as it is presented in the results.

Some of the years where there is plugging occurring as presented in 1D model figures that are impacting on the reservoir liquid rate, oil rate during production process taken into consideration.

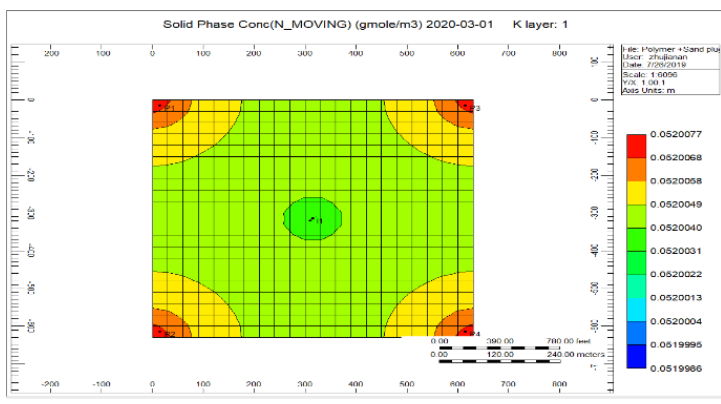

Figure 4. Indicating the solid phase concentration toward the production well

Fig. 5. Indicates there is a concentration of sand in the surrounding of production well, with a range of 0.0520077, whereas the solid concentration steadily declines toward the injector well with a range of 0.0520031 . sand plug model with different colour scale range indicate the arrival of sand into the production well from smaller range into a bigger range in the function of time.

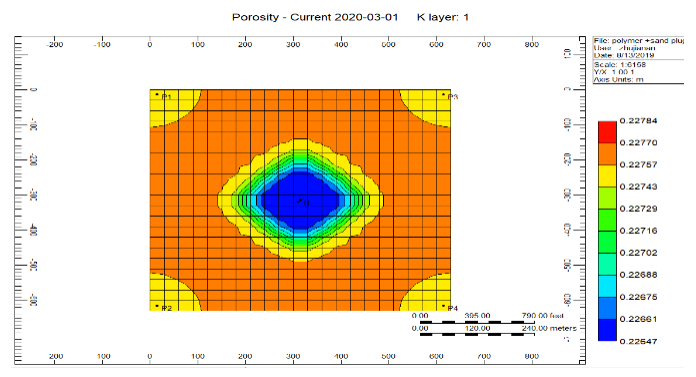

Fig. 5. Porosity reduction during polymer sand plug model 
Fig. 6. Porosity reduction during polymer sand plug model, the yellow porosity decrease sighted at the location of producer well ranges to 0.22743 . But in the middle of the model surrounding the injector well porosity decrease with a lower range of 0.22647. That is due to the presence of mechanical entrapment, debris provoking porosity to decrease.

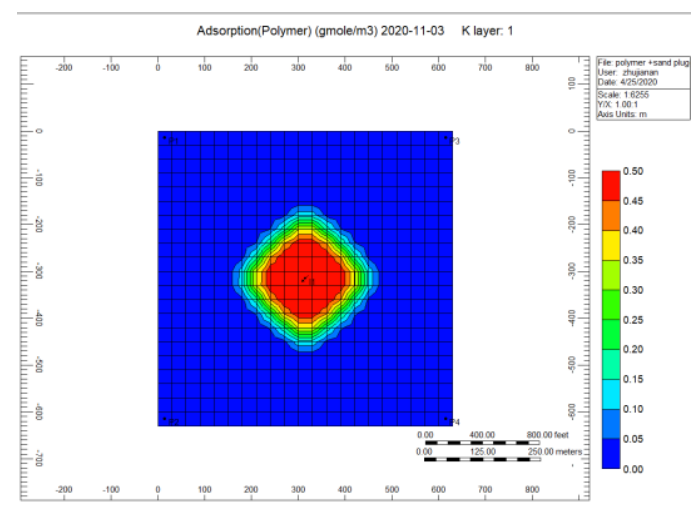

Fig. 6. Polymer adsorption during polymer sand plug model

Fig. 7. Polymer adsorption during polymer sand plug model, we observed that on the figure that there is a high adsorption of polymer surrounding the injector well with a range of 0.50 , whereas the range surrounding the producer well range 0.01 to 0.00 .

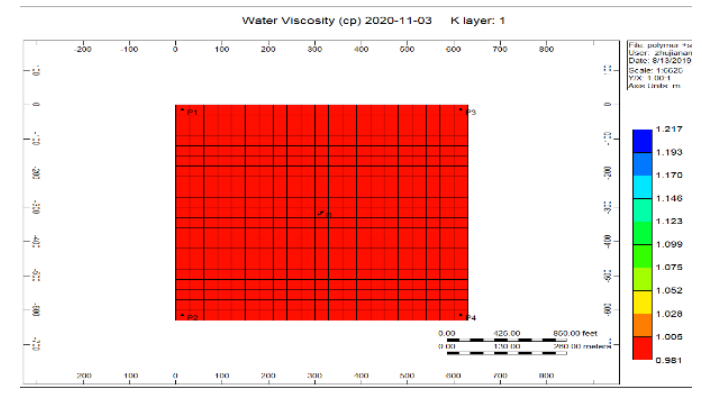

Fig. 7. Water viscosity during polymer sand plug model

Fig. 8. Water viscosity during the polymer sand plug model, with the degradation of the polymer, the viscosity decreased to it is lowest during injection of polymer flooding toward the injector well as well the producer well. The viscosity rate reduction reached to the highest rate of 0.981 .

The continuous rate decrease is due to the high presence of sand solid concentration component reaction of non-moving 'N_MOVING' and the moving SAND which is present in the oil affecting during the polymer flooding. This high rate drop is also due to high sand solid concentration size $(0.052)$, as well the
FREQFACT of 0.031 affects the liquid and the oil rate to decrease continuously.

Based on our results, we can observe that the parameters affecting the liquid rate, oil rate to drop due to the presence of sand particles, debris which causing plugging during polymer flooding as following: polymer adsorption, polymer degradation, permeability reduction, porosity decrease, inaccessible pore volume, water viscosity, the high concentration of solid phase and the high reactant frequency factor with a high rate could influence badly the liquid rate, oil rate to decrease quickly or slowly based on the parameters value of (reactant frequency factor and the concentration of solid phase), and will lead to production loss.

Fig. 9. Polymer sand plug model liquid rate reached on it is highest to $25 \mathrm{~m}^{3} /$ day in 2014-081 slowly dropping till it has reached a rate of 14.67 $\mathrm{m}^{3} /$ day in 2019-04-1, then the rate continuously dropping till it has reached on it is lowest in 202003-1 to $13.85 \mathrm{~m}^{3} /$ day.

With this continuous production liquid rate drop, from the year 2014-08-01 to 2015-07-08 a rate of $1.409 \mathrm{~m}^{3} /$ day been lost, as time goes the production rate loss is increasing; from the year 2015-07-08 to 2016-06-1 a rate of $3.191 \mathrm{~m}^{3} /$ day lost. On a difference of 3 to 4 years the loss is significant; 2016-06-1 to 2020-03-1 a total rate of $10.391 \mathrm{~m}^{3} /$ day. Whereas the production oil rate loss started from the year 2017-01-01 to 2018-031 lost a rate of $4.64 \mathrm{~m}^{3} / \mathrm{day}$. Finally, from the year 2018-03-01 to 2020-03-01 the loss is less compare to previous years with an oil rate loss of $2.36 \mathrm{~m}^{3} /$ day.

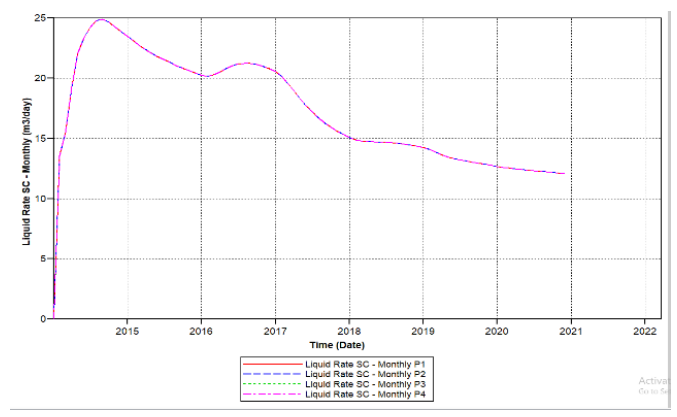

Fig. 8. Polymer sand plug model liquid rate

Fig. 10. polymer sand plug model oil rate, the rate is on rising reached to $20.1 \mathrm{~m}^{3} /$ day in $2015-07-08$ but started decreasing from 2016-02-1 till it has reached to a lower rate of $12.56 \mathrm{~m}^{3} /$ day in 2020 03-01. 


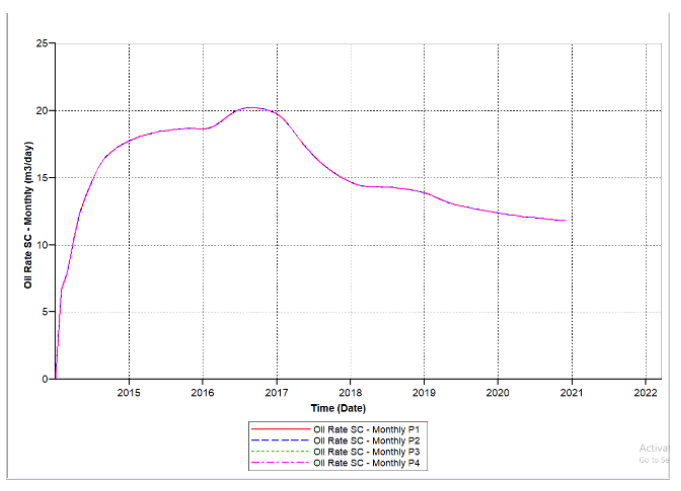

Fig. 9. Polymer sand plug model oil rate

\section{2) BASE CASE: CROSSLINKED GEL MODEL}

As the sand plugging phenomenon occurring during the polymer flooding affecting the liquid rate and oil rate to drop continuously, searching for a preventive treatment to minimize polymer plugging and improving the liquid and oil rate is very necessary.

The polymer sand plug model with the same parameters investigated under crosslinked gel performance for the reason of decreasing due to plugging impact. With the application of a crosslinked gel approach, the affected parameters such as; cross-linked gel adsorption, permeability, porosity, water viscosity, the concentration of solid phase decreased and the liquid production rate has been improved with the removal of plugging.

In Gao-Qian-Bei block in the Ji-Dong field, Shengli experiencing an active edge aquifer water, a cross-linked polymer applied in order to enhance the oil recovery [46].

Gel conformance treatment broadly applied around the world for it is efficiency. Discussed by Seright, the preliminary discussion is to point out the main differences between a gel used for reservoir conformance control and a polymer flood. Conventional gels used in "conformance control" are intended to block or reduce the flow capacity of high-permeability channels without damaging the less-permeable hydrocarbon productive zones. It is therefore compulsory to minimize penetration of gelants into the less permeable zones [47].

Fig. 11. Indicate the Crosslinked gel solid phase concentration toward the production well, in the final year, we can remark that the solid phase concentration ranges from 0.00012 to 0 compare to Fig. 5. Indicates there is a concentration of sand in the surrounding of production well, the solid phase concentration is highly concentrated toward the model. With the application of crosslinked gel, the solid debris presence can be reduced.

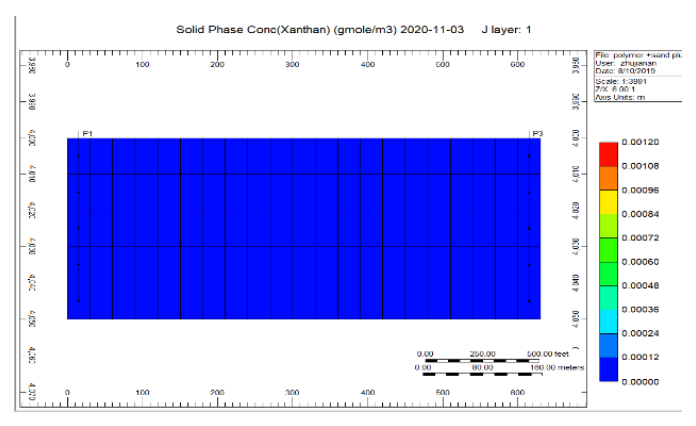

Fig. 10 . Indicate the Crosslinked gel solid phase concentration toward the production well

Fig. 12. Porosity increase of the crosslinked gel performance model, the porosity at the location of an injection well with an increasing range of 0.2277800 .

But at the position of the producer well decreased to a range of 0.227782. Comparing to Fig. 6 . Porosity reduction during the polymer sand plug model, the porosity has been improved.

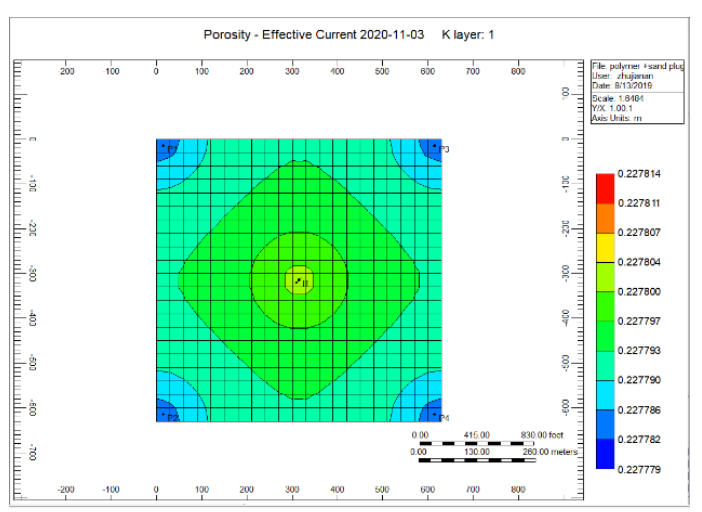

Fig. 11. Porosity increase of the crosslinked gel performance model

Fig. 13. Gel adsorption of the crosslinked gel performance model, in the final year we can see that the crosslinked gel is highly adsorbed with a range of 0.0226 in the entire model compare to Fig. 7. Polymer adsorption during polymer sand plug model, the absorption is highly concentrated toward the injector well. 


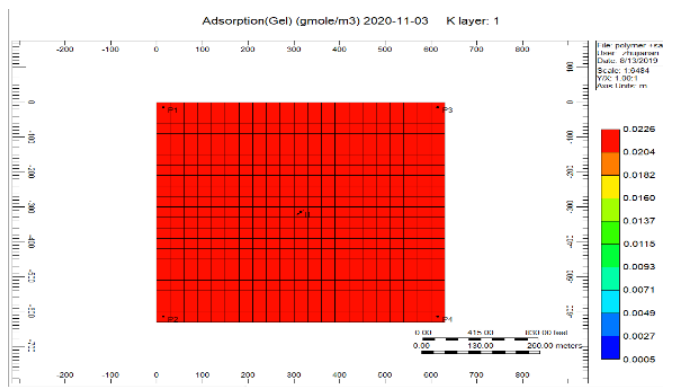

Fig. 12. Gel adsorption of the crosslinked gel performance model

Fig. 14. Water viscosity of the crosslinked gel performance model, the viscosity of the water has increased with a range of 0.994 surrounding the injector well and a range of 0.991 for the rest of the model. Comparing to Fig. 8. Water viscosity during polymer sand plug model is 0.981 due to plugging occurring during polymer flooding in the reservoir, a concentration of solid sand/sand particle moving into the production well affecting the liquid rate and the oil rate to drop in function of the sand solid concentration size toward the production well.

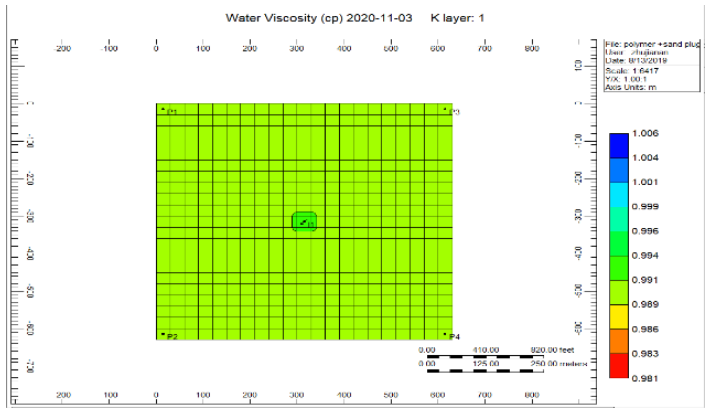

Fig. 13. Water viscosity of the crosslinked gel performance model

We observe on the result after the application of cross-linked gel treatment the impact has been minimized and the result has been improved. On the graph result of; Fig. 15. Liquid rate after crosslinked gel treatment graph and Fig. 16. Oil rate after crosslinked gel treatment graph, which crosslinked gel achieved good results; the plugging has significantly decreased on the liquid rate and oil rate graphs curve even though we can observe some decrease on the graphs. That means, with the application of crosslinked gel performance the parameters affecting the liquid rate and oil rate are treated. The application of crosslinked gel supply shear solidity, assuring thermal solidity, erosion immunity for the reason of it is a vigorous gel network.
Fig. 15. Liquid rate after crosslinked gel treatment graph, we can observe on the result that the liquid rate started increasing from; 2014-0201 till it has achieved the highest rate of 21.609 $\mathrm{m}^{3} /$ day in 2015-01-01, then dropped to it is lowest $19.51 \mathrm{~m}^{3} /$ day in $2020-02-1$, without reaching a period of 1 month the rate rising back but it does not reach $20 \mathrm{~m}^{3} /$ day.

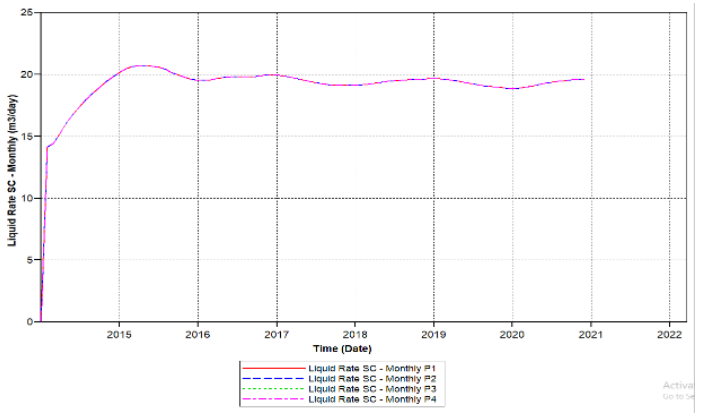

Fig. 14. Liquid rate after crosslinked gel treatment graph

Fig.16. Oil rate after the crosslinked gel treatment graph started increasing it has reached a rate of $14.45 \mathrm{~m}^{3} /$ day in 2015-09-01 then the oil rate dropped to $15.213 \mathrm{~m}^{3} /$ day in $2017-07-01$ to 2018 01-01. With the decrease, the rate increased back starting from 2018-02-01 to 2019-01-01 the rate reached $15.47 \mathrm{~m}^{3} /$ day. In the year $2020-02-01$, the rate dropped and reached a lower rate of $14.91 \mathrm{~m}^{3} /$ day, finally, the curve has risen to 15.31 $\mathrm{m}^{3} /$ day for the rest of the simulation.

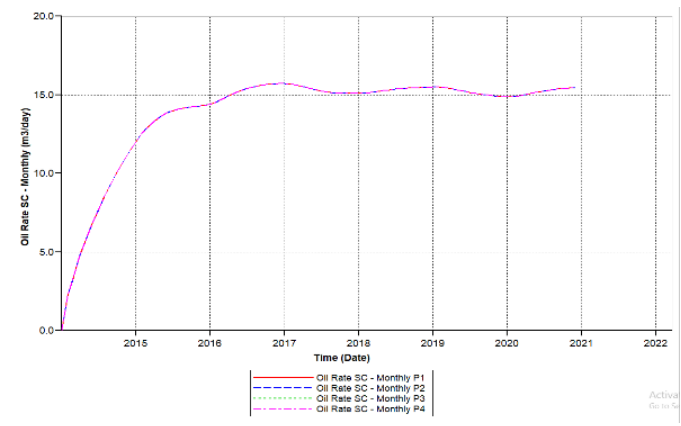

Fig. 15. Oil rate after crosslinked gel treatment graph

\section{B. Sensitivity analysis}

With the effects of a liquid rate decrease, oil rate decreasing continuously as we could observe during polymer flooding of Polymer sand plug model and Cross-linked gel performance model were compared each other as described below;

1) CASE 1: POLYMER SAND PLUG MODEL

We have decreased the initial solid concentration size from 0.052 of the initial model with continuous lower concentration rate of 0.023 , and the activation of energy component reaction 
frequency factor decreased to (FREQFACT= 0.002312 ) due to the continuous drop of the liquid rate and oil rate of the initial polymer sand plug model (Fig. 9., Fig. 10.).

We can see that with the decrease of solid phase concentration, component reaction frequency factor decrease, Fig. 17. Indicates there is a concentration of sand in the surrounding of production well, Fig. 18. Porosity reduction during polymer sand plug model, Fig. 19. Polymer adsorption during polymer sand plug model, Fig. 20. Water viscosity of the polymer sand plug model all have been improved as well the liquid rate, and the oil rate does not decrease continuously as it has occurred with the base case model graph curves (Fig. 9. Polymer sand plug model liquid rate, Fig. 10. Polymer sand plug model oil rate). The liquid rate and oil rate are affected by the decrease due to the plugging effect as we can see on curve graphs of; Fig. 21. Polymer sand plug model liquid rate, Fig. 22. Polymer sand plug model oil rate.

Fig. 17. Indicate the solid phase concentration toward the production well, we can observe that the solid phase concentration at the first layer with a range of 0.049 , whereas the rest layers are 0.046 .

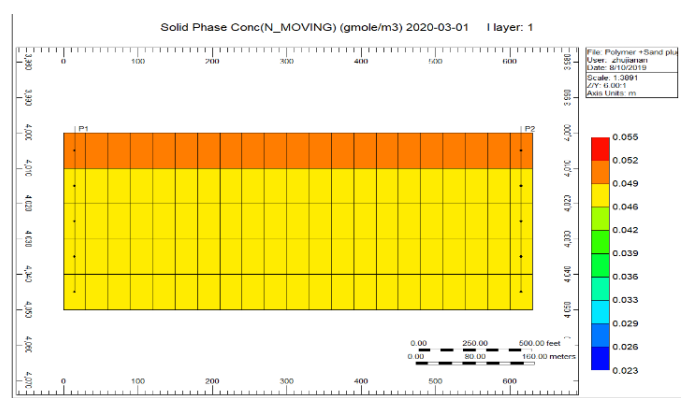

Fig. 16. Indicate the solid phase concentration toward the production well

Fig. 18. Porosity reduction during polymer sand plug model, the porosity range toward the injector well is 0.22563 , surrounding the producer well ranges 0.22780 .

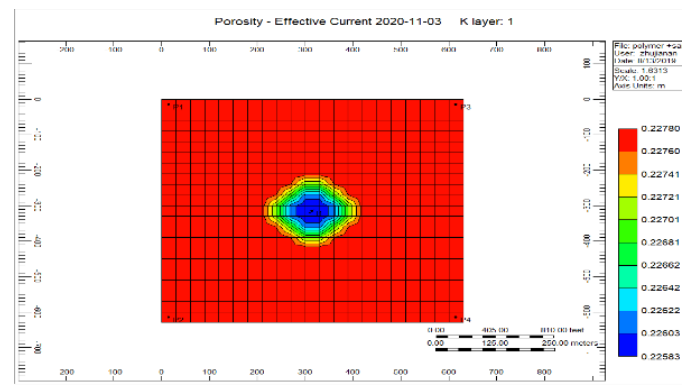

Fig. 17. Porosity reduction during polymer sand plug model

Fig. 19. Polymer adsorption during polymer sand plug model, the polymer adsorption is highly absorbed around the injector well with a range of 0.90 , whereas the adsorption is very low toward the rest of the model with a range of 0.1 to 0.00 .

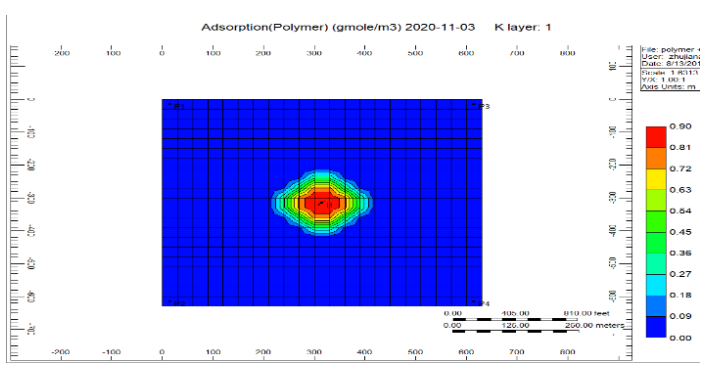

Fig. 18. Polymer adsorption during polymer sand plug model

Fig. 20. Water viscosity of the polymer sand plug model, the viscosity of water around the injector well with a range of 0.9853 and surrounding the producing well is 0.9809 .

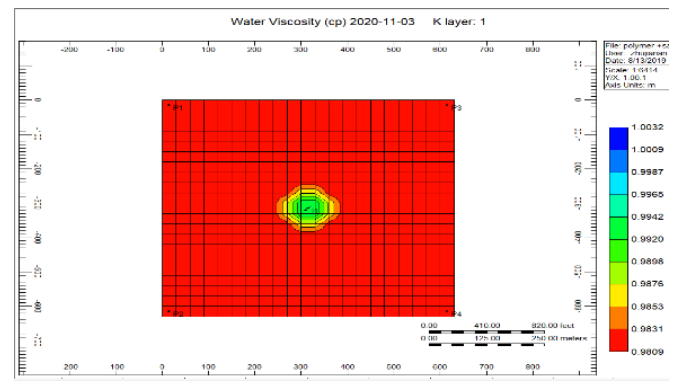

Fig. 19. Water viscosity of the polymer sand plug model

Fig. 21. polymer sand plug model liquid rate, the liquid rate has reached on it is highest to 25.809 $\mathrm{m}^{3} /$ day in 2014-08-1, the rate slowly decreasing and increasing from time to time, in the year 2018-03-02 reached a rate of $23.45 \mathrm{~m}^{3} /$ day. Then the liquid rate slowly started increasing till it has reached a pick rate of $24.7 \mathrm{~m}^{3} /$ day in 2019-04-1, then slowly the rate started dropping till it has reached on lowest in 2020-03-1 to $23.85 \mathrm{~m}^{3} /$ day. We can still see on the graph that the rate started 
increasing for the rest of the simulation (2020-12$1)$.

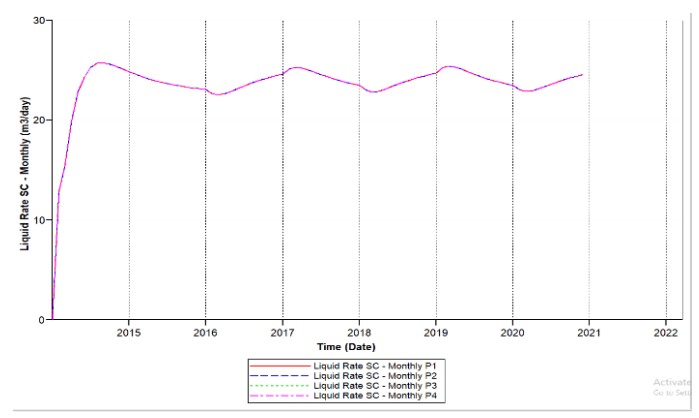

Fig. 20. Polymer sand plug model liquid rate

Fig. 22. polymer sand plug model oil rate, whereas the oil rate reached on it is highest to 12.2 $\mathrm{m}^{3} /$ day in 2014-08-1 and dropped to $11.97 \mathrm{~m}^{3} /$ day in 2014-12-1, we can observe that in the year 2014 the oil rate does not reach to it is the highest rate that is due to the quick rise and quick drop. An increased rate of $12.4 \mathrm{~m} 3 /$ day in 2017-04-1, within 2 months the oil rate started decreasing continuously till reached $11.86 \mathrm{~m}^{3} /$ day in 2018 03-1. From the decrease, the oil rate started recovering until it has achieved a high rate compared to the previous years, a rate of 12.58 $\mathrm{m}^{3} /$ day achieved in 2019-04-1. The rate decreased for a moment but recovering for the rest of the simulation.

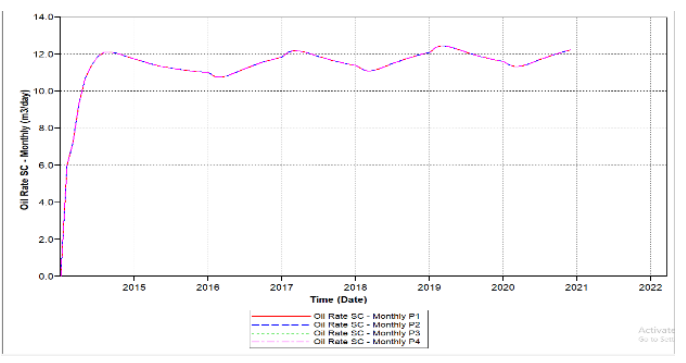

Fig. 21. Polymer sand plug model oil rate

CASE 2: CROSSLINKED GEL MODEL

The solid phase concentration set at the same as the polymer sand plug model case 1 (0.023), and the frequency reaction factor reduced to 0.000002 . The lower frequency factor performs a better result on the crosslinked gel performance model base case.

Fig. 23. Porosity increased during crosslinked gel performance 2020-11-03, the increase of porosity surrounding the injection well with a range of 0.227799 , will also increase the porosity toward the rest of the model with a range of 0.227784 .

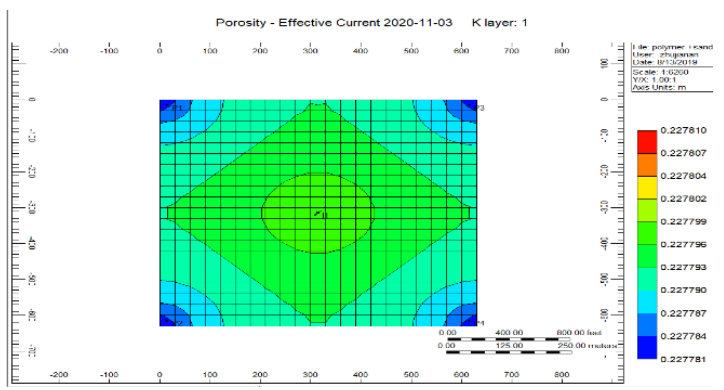

Fig. 22. Porosity increased during crosslinked gel performance 2020-11-03

Fig. 24. Gel adsorption crosslinked performance model 2020-11-03, gel cross-linked is highly adsorbed toward the whole model ranges 0.0178 , and whereas surrounding the injector well the adsorption is lower with a range of 0.018 .

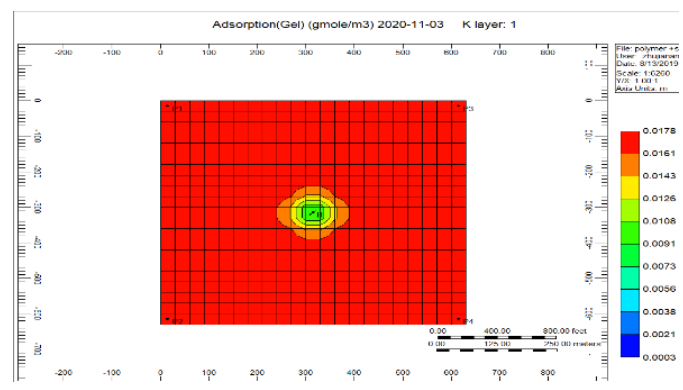

Fig. 23. Gel adsorption crosslinked gel performance model 2020-11-03

Fig. 25. Water viscosity cross-linked gel performance 2020-11-03, we can observe on the figure that the viscosity ranges 0.987 surrounding the injector well, whereas the rest of the model ranges 0.982 .

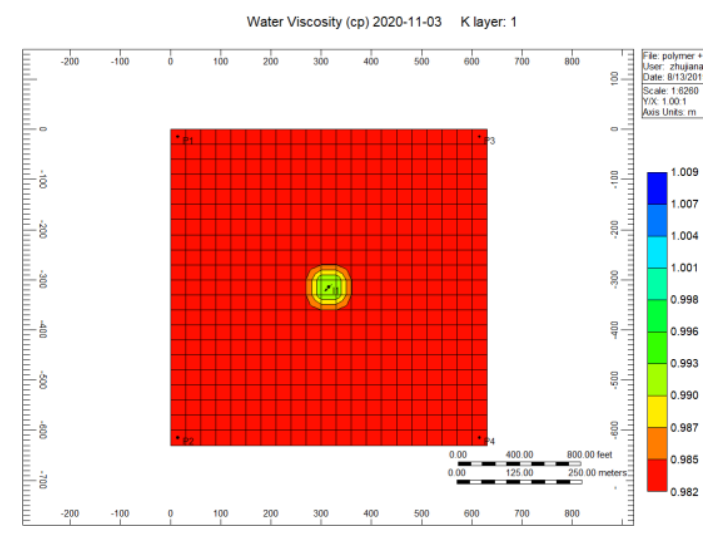

Fig. 24. Water viscosity crosslinked gel performance 202011-03

We can observe based on the result analysis that, with the decrease of solid phase concentration, frequency reaction factor reduction to lower rate compared to the previous Fig. 15. Liquid rate after 
cross-linked gel treatment graph, the current Fig. 26. Liquid rate after cross-linked gel treatment graph, performed far better results with almost no plugging effects, with a higher liquid rate compare to Fig. 15. But the current graph, Fig. 27. The oil rate after the cross-linked gel treatment graph, shows no plugging occurring on the curve graph, but the oil rate is less than Fig. 16. Oil rate after cross-linked gel treatment graph.

Fig. 26. Liquid rate after cross-linked gel treatment graph, with the solid phase concentration decrease, and the frequency reaction factor decrease we could observe on the graph that the liquid significantly increasing without experiencing liquid rate decrease. The liquid with a starting rate of $23.5 \mathrm{~m}^{3} /$ day from the year 2014-03-01 to 2015-10-01, continuously increasing without rate drop reached $24.5 \mathrm{~m}^{3} /$ day in 2017-01-01. With stead forward liquid rate increasing, in the year 2019-01-01 reached the highest rate of $25.4 \mathrm{~m}^{3} / \mathrm{day}$, the liquid rate stable till 2020-12-01.

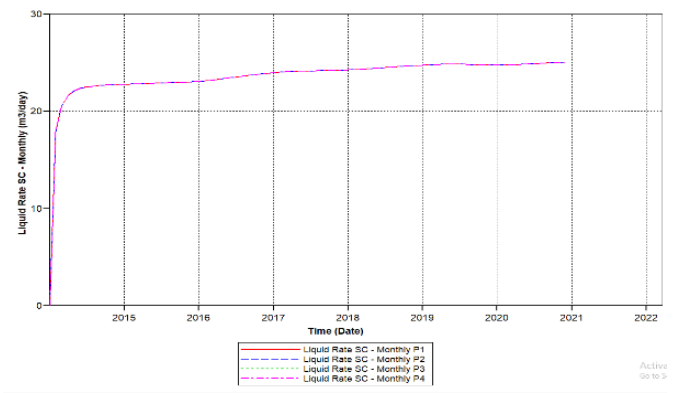

Fig. 25. Liquid rate after crosslinked gel treatment graph

Fig. 27. Oil rate after cross-linked gel treatment graph, with lower solid phase concentration and frequency reaction factor, oil rate started increasing continuously without experiencing any drop from the year 2014-01-01 till it has reached it is highest rate $15.2 \mathrm{~m}^{3} /$ day in $2020-12-01$.

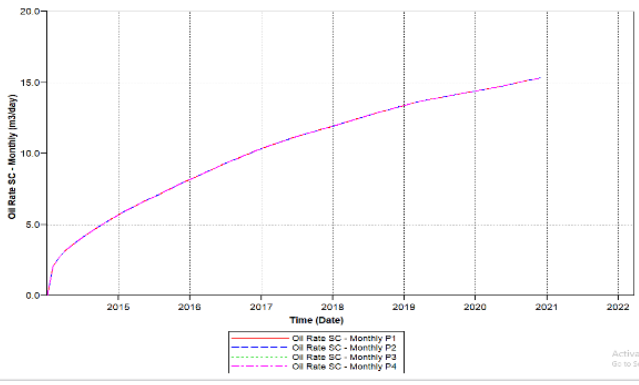

Fig. 26. The oil rate after the crosslinked gel treatment graph
It is remarked depend on the base cases (polymer flood model, crosslinked gel model) and the sensitivity analysis cases (polymer flood model, crosslinked gel model) the liquid rate, oil rate of polymer model decrease faster and unstable apart from the crosslinked gel stable.

The bigger the SOLIDMIN and the FREQFAC, the worst the liquid rate, oil rate that can be remarked on the base case (polymer flood model).

The main parameters of the plugging mechanism which causing production liquid decrease investigated and improved as follows:

1. Solid phase concentration toward the wells and FREQFACT are the main influences causing plugging and leading the production rate to decrease.

2. During polymer flooding the liquid rate, oil rate decreased due to the plugging mechanism, the application of crosslinked gel ameliorated reservoir production rate.

3. With the application of polymer flooding, the viscosity has increased with the plugging effect, but water viscosity decreased, improved the displacement with the application of crosslinked gel.

\section{Conclusions}

Based on our results it can be concluded that the parameters affecting on the reservoir are stated as below:

- The parameters affecting the liquid rate, oil rate to drop due to the presence of sand particles, debris which causing plugging during polymer flooding as following: Polymer adsorption, polymer degradation which affects the permeability to decrease, porosity decrease, inaccessible pore volume, water viscosity, the high concentration of solid phase and the high reactant frequency factor with a high rate could influence badly the liquid rate, oil rate to decrease quickly or slowly based on the parameters value of (reactant frequency factor and the concentration of solid phase) and will lead to production loss.

- As the sand plugging phenomenon occurring during the polymer flooding affecting the liquid rate and oil rate to drop continuously, searching for a preventive treatment to minimize 
polymer plugging and improving the liquid and oil rate is very necessary.

- We could observe on the result that after the application of cross-linked gel treatment on the polymer sand plugged model impact has been minimized and the result has been improved.

- Cross-linked gel adsorption, permeability, porosity, water viscosity, the concentration of solid phase has been ameliorated and the production liquid has been improved.

- Cross-linked gel achieved good results; the plugging has been significantly decreased on the liquid rate and oil rate even though we can observe some decrease.

- The application of cross-linked gel supply shear solidity, assuring thermal solidity, erosion immunity for the reason of it is a vigorous gel network.

\section{Nomenclature}

$q_{L}=$ Defined as the liquid rate measured per meter $\mathrm{m}^{3} / \mathrm{d} / \mathrm{m}$;

$P_{e}={ }_{\text {Is the reservoir pressure, } \mathrm{MPa}}$

$P_{w f=}$ Is the Bottom Hole Pressure (BHP), $\mathrm{MPa}$

$t=$ Time during the development stage

$\mathrm{i}=$ Time during the initial stage

$A D S R O C K=$ Represent the adsorption of the present rock, Dimensionless

$A D M A X T=$ Represent the maximum adsorption capacity, Dimensionless

$A D R T=$ Indicate the residual adsorption level, Dimensionless

$A D S P H B L K=$ Represent the adsorption of the block phase description $(O, W)$

PORFT $=$ Indicate the accessible pore volume or fraction of the available pore volume, it can also be considered as the fraction of pore volume that is inaccessible to the component. Dimensionless

RRFT $=$ Residual Resistance Factor of the adsorbing component, dimensionless

SOLIDMIN $=$ Solid phase concentration

$F R E Q F A C=$ Reacting frequency factor

FREQFACT $=$ The effect of reaction frequency activation energy

$\mathrm{K}_{b p}=$ Indicate absolute rock permeability prior to polymer flooding, Darcy

$R_{k}=$ Indicate the permeability reduction factor, Darcy

$\bar{K}=$ Absolute permeability, Darcy

$R_{K W}=$ Indicate the permeability reduction of the water phase component, Darcy

$R_{K O}=$ Indicate the permeability reduction of the oil phase component, Darcy

$C=$ Represent the adsorption obtained from the concentration

$T=$ Temperature obtained from the concentration condition factor, ${ }^{\circ} \mathrm{C}$

$\lambda_{W b}=$ Mobility of the water before treatment, $\lambda_{W a}=$ Mobility of the water after treatment,

$K_{w b}=$ Permeability of the water before treatment, Darcy

$K_{W a}=$ Permeability of the water after treatment, Darcy 
$\mu_{W b}=$ Viscosity of the water before treatment, $\mathrm{cP}$

$\mu_{W a}=$ Viscosity of the water after treatment, cP

$\boldsymbol{L} \boldsymbol{e}=$ Indicate the length, $\mathrm{m}$

$L a=$ Indicate each layer,

$K_{p o}=$ Effective permeability of the polymer solution, Darcy

$\phi_{p}=$ Indicate the polymer porosity, $\%$

\section{Acknowledgments}

The authors thank the support provided by the State Key Laboratory of Offshore Oil Exploitation, Beijing 100028, China, with the following research project: Research on polymer flooding mechanism on liquid production decrease in polymer flood oilfield.

\section{Conflicts of Interests}

The authors declare no conflict of interest.

\section{References}

[1] C. M. Gasda SE, Wang JZ, Duguid A, "Wellbore permeability estimates from vertical interference testing of existing wells. ," Energy Procedia vol. 37:56735680, 2013.

[2] V. R. Mohan KK, Reed MG, Fogler HS "Water sensitivity of sandstones containing swelling and non-swelling clays. ," Colloid Surf, vol. A 73:237-254, 1993.

[3] F. H. Vaidya RN, "Formation damage due to colloidally induced fines migration.," Colloid Surf, vol. 50:215-229, 1990.

[4] D. Y. Chen ZH, "Actuality at outlook of acid-fracturing technique in deep carbonate formation. ," Pet Drill Tech, vol. 33:58-62, 2005.

[5] B. H, "Stress-induced permeability reduction in fissured reservoirs.," SPE annual technical conference and exhibition, Houston, TX, USA, vol. , 1993.
[6] B. B. Sadeghazad Y, "Unusual carbonate rocks showing increasing trends for rock compressibility as the applied net stress increases," SPE Asia Pacific oil and conference and exhibition, Jakarta, Indonesia, 2003.

[7] K. Y. Wu J, Li YQ "Research on variation of velocity sensitivity and water sensitivity before and after acid etching in carbonate reservoir.," Drill Prod Technol vol. 30:105107, 2007.

[8] B. P. Buijse M, Breukel B, Burgos G "Organic acids in carbonate acidizing. ," SPE Prod Facil, vol. 19:128-134, 2004.

[9] K. GE, "Acidizing concepts-matrix vs. fracture acidizing.," J Pet Technol, vol. 38:507-508, 1986.

[10] N.-E.-D. H. Pournik M, Mahmoud MA, "A novel application of closed-fracture acidizing. ," SPE Prod Oper vol. 26:18-29, 2011.

[11] E. S. Wahib S, Choo DJ, Seng WC, Ramnarine RP "Acidizing: a small change in recipe, a big improvement in production,"

SPE Asia Pacific oil and gas conference and exhibition, Brisbane, QLD, Australia, 2010.

[12] Sheng, "Enhanced oil recovery field case studies. ," Gulf Professional Publishing, Waltham, 2013.

[13] L. B. Sheng JJ, Azri N, " Status of polymerflooding technology.," J Can Pet Technol, vol. 54:116-126., 2015.

D. J. Abbas S, Sanders A "Applicability of hydroxyethylcellulose polymers for chemical EOR.," SPE Enhanced Oil Recovery Conference. Soc. Pet. Eng. J. SPE165311-MS. , 2013.

[15] S. I. Standnes DC, " Literature review of implemented polymer field projects. ," J Pet Sci Eng, vol. 122:761-775., 2014.

[16] Sen R, "Biotechnology in petroleumrecovery: the microbial EOR.," Prog Energy Combust Sci., vol. 34:714724. , 2008.

[17] S. N. Gassara F, Stanislav P, Voordouw G, "Microbially enhanced oil recovery by sequential injection of light hydrocarbon and nitrate in low- and high-pressure bioreactors. ," Environ Sci Technol vol. 49:12594-12601. , 2015.

[18] M. D. Kantzas A, Allsopp K "Utilization of polymer gels, polymer enhanced foams, and foamed gels for improving reservoir conformance," J Can Pet Technol vol. 38(13):1-8, 1999.

[19] Z. L. Hua, M.; Guo, J.; Xu, F.; Li, Z.; Li, M. , "Study on plugging performance of cross-linked polymer microspheres with reservoir pores," J. Pet. Sci. Eng. , vol. 105, 70-75., 2013. 
[20] H. Q. Z. Liu, H.L.; Wang, S.; Wang, H.; Bao, S.H., "Research on mechanisms of steam breakthrough and profile control design for steam soaking well. ," Pet. Sci. , vol. 51-55., 2006.

[21] M. Z. Lin, G.; Hua, Z.; Zhao, Q.; Sun, F. , "Conformation and plugging properties of crosslinked polymer microspheres for profile control. ," Colloid Surface A, vol. 477, 49-54. , 2015.

[22] F. L. Sun, M.; Dong, Z.; Zhu, D.;Wang, S.L.; Yang, J., " Effect of composition of HPAM/chromium(iii) acetate gels on delayed gelation time.," J. Dispers. Sci. Technol. , vol. 37, 753-759., 2016.

[23] S. Vossoughi, " Profile modification using in situ gelation technology-A review. ," $J$. Pet. Sci. Eng. , vol. 26,199-209., 2000.

G. D. Zhao, C.; Chen, A.; Yan, Z.; Zhao, M., " Experimental study and application of gels formed by nonionic polyacrylamide and phenolic resin for in-depth profile control," J. Pet. Sci. Eng. , vol. 135, 552-560., 2015.

[25] X. L. Lu, J.;Wang, R.; Liu, Y.; Zhang, S., "Study of action mechanisms and properties of $\mathrm{Cr} 3+$ cross-linked polymer solution with high salinity. ," Petrol. Sci., vol. 9, 75-81., 2012.

[26] L. Z. Zhang, L.; Pu, J.; Pu, C.; Cui, S. , "Influence of HPAM molecular weight on the cross-linking reaction of HPAM/Cr3+ and transportation of HPAM/Cr3+ in microfractures. ," Energy Fuel, vol. 30, 93519361., 2016.

[27] D. C. H. Bassett, A.G.; Melø, T.B.; Stokke, B.T.; Sikorski, P. , "Competitive ligand exchange of crosslinking ions for ionotropic hydrogel formation. ," J. Mater. Chem. B, vol. 4, 6175-6182., 2016.

[28] C. L. Gu, Y.; Fan, X.; Zhao, C.; Dai, C.; Zhao, G., "Study on rheology and microstructure of phenolic resin cross-linked nonionic polyacrylamide (NPAM) gel for profile control and water shutoff treatments.," J. Pet. Sci. Eng., vol. 169, 546552., 2018.

[29] H. P. Jia, W.; Zhao, J.; Liao, R., "Experimental investigation of the novel phenol-formaldehyde cross-linking HPAM gel system: Based on the secondary crosslinking method of organic cross-linkers and its gelation performance study after flowing through porous media. ," Energy Fuel, vol. 25, 727-736., 2011.

[30] F. L. Wei, Y.; Yue, X.; Hou, J.; Tang, X.; Li, Y.; Xiong, C.; Liu, G., "Thermal stability and transport property of multiple emulsions used as delayed crosslinker. ," Acta Petrol. Sin., vol. 29, 423-426., 2008.

[31] B. Z. Xu, J.; Hu, X., "The Delayed Crosslinking Amphiphilic Polymer Gel System Based on Multiple Emulsion for inDepth Profile Control. ," J. Dispers. Sci. Technol. , vol. 38, 1242-1246., 2017.

[32] S. A. Abhijit, B.; Keka, O.; Ajay, M., "Effects of alkali, salts, and surfactant on rheological behaviour of partially hydrolysed polyacrylamide solutions.," $J$. Chem. Eng. , vol. 55, 4315-4322., 2010.

[33] A. B. Sabhapondit, A.; Haque, I., "Characterization of acrylamide polymers for enhanced oil recovery.," J. Appl. Polym. Sci., vol. 87, 1869-1878., 2003.

[34] R. M. Vinu, G., "Photocatalytic degradation of poly(acrylamide-co-acrylic acid). ," $J$. Phys. Chem., vol. B 112, 8928-8935., 2008. [35] M. H. Yang, "The rheological behavior of polyacrylamide solution.," J. Polym. Eng. , vol. 19, 371-381., 1999.

[36] M. L. S. Hoefner, R.V.; Shu, P.; Phelps, C.H., "Selective penetration of biopolymer profile-control gels: Experiment and model.," J. Pet. Sci. Eng. , vol. 7, 53-66., 1992.

[37] C. N. Chassenieux, T.; Benyahia, L., "Rheology of associative polymer solutions. Curr. Opin.," Colloid Interface Sci., vol. 16, 18-26., 2011.

[38] S. H. Dastan, S.; Abdollahi, E., "Hydrophobically associating terpolymers of acrylamide, alkyl acrylamide, and methacrylic acid as EOR thickeners.," $J$. Polym. Res., vol. 23, 175., 2016.

[39] N. D. Lai, W.; Ye, Z.; Dong, J.; Qin, X.; Chen, W.; Ke, C., "A water-soluble acrylamide hydrophobically associating polymer: Synthesis, characterization, and properties as EOR chemical. ," 129, 18881896., vol. J. Appl. Polym. Sci., 2013.

[40] C. L. N. McCormick, T.; Johnson, C.B., "Water-soluble copolymers: 27. Synthesis and aqueous solution behavior of associative acrylamide/ $\mathrm{N}$-alkylacrylamide copolymers. ," Polymer vol. 29, 731-739., 1988.

[41] K. C. N. Taylor, A., "Water-soluble hydrophobically associating polymers for improved oil recovery: A literature review. ," J. Pet. Sci. Eng., vol. 192, 265280., 1998.

[42] P. F. Wever D. A. Z., Broekhuis A. A., , "Polymers for Enhanced Oil Recovery: A Paradigm for Structure-Property Relationship in Aqueous Solution ," Progress in Polymer Science 36, vol. 15581628, 2011.

[43] P. W. Zhang, Y.; Chen, W.; Yu, H.; Qi, Z.; Li, K. , "Preparation and solution 
characteristics of a novel hydrophobically associating terpolymer for enhanced oil recovery.," J. Solut. Chem. , vol. 40, 447457., 2011.

[44] C. J. Zhong, L.; Peng, X. , "Synthesis and solution behavior of comb-like terpolymers with poly(ethylene oxide) macromonomer. Part A Polym. Chem.," J. Polym. Sci., vol. 48, 1241-1250., 2010.

[45] C. W. Zhong, W.; Yang, M. , "Synthesis and solution properties of an associative polymer with excellent salt-thickening.," J. Appl. Polym. Sci. , vol. 125, 4049-4059., 2012.

[46] D. Q. D. Zhuang, A.H.; Zhang, Y.X.; Dieing, R.; Ma, L.; Haeussling, L., "Hydrophobically modified polyelectrolytes II: Synthesis and characterization of poly(acrylic acid-co alkylacrylate). ," Polym. Adv. Technol., vol. 12, 616-625., 2001.

[47] Z. Li., and Delshad, M.,, "Development of an Analytical Injectivity Model for NonNewtonian Polymer solutions. ," SPE 163672., vol. 19(03): 381-389, 2014.

[48] C. Yuan, . Delshad, M. and Wheeler, M.F., "Modeling Multiphase Non-Newtonian Polymer Flow in IPARS Parallel Framework.," Network and Heterogeneous Media, vol. 5(3): 583-602., 2010.

[49] G. J. a. P. Hirasaki, G.A., , Analysis of Factors Influencing Mobility and Adsorption in the Flow of Polymer Solution Through Porous Media.," SPE, vol. 14(04):337-346. 4026, 1974.

[50] L. W. Lake, Johns, R. T., Pope, G. A, and Rossen, W.R. ,"Fudamentals of Enhance Oil Recovery.," SPE, 2014.

[51] B. Brattekas, ; Steinsbo, M.; Graue, A; Ferries, M.A.; Espedal, H.; Seright, R.S., , "New Insight into Wormhole Formation in Polymer Gel during Water Chases Floods with Positron Emission Tomography. ," SPE, vol. 32-40., 2017.

[52] B. J. L. Bai, L.X; Liu, H.; Wang, Z.G.; You, C.M. ," "Preformed particle gel conformance control: factor affecting it is property and applications.," SPE, vol. 415-422., 2007.

[53] L. Surguchev, "Well Shut-off TreatmentsNear Well Simulation and Evaluation.," presented at the European Symposium and on IOR, 1997.

[54] L. A. Saputelli, Canache,P. and Lopez,E, "Application of a Nonequilibrium Reaction Model for Describing Horizontal Well Performance in Faomy Oils. ," SPE, 1998.

S. K. Rai, Bera, A. \& Mandal, A. , "Modeling of surfactant and surfactantpolymer flooding for enhanced oil recovery using STARS (CMG) software," J Petrol Explor Prod Technol vol. 5, 1-11, 2015.

[56] T. Scott, Roberts, L.J., Sharpe, S.R., Clifford, P.J., and Sorbie, K.S.," In-situ Gel
Calculations in Complex Reservoir Systems Using a New Chemical Flood Simulator.," SPE, 1987.

[57] M. A. J. V. Cziple F. A., "Biopolymers versus Synthetic Polymers," 2008.

[58] A. A. Olajire, "Review of Alkaline Surfactant Polymer Flooding Enhance Oil recovery Technology in Petroleum Industry," j.energy., 2014.

[59] T. P. A.Z.Abidin, W.A. Nugoroho, "Polymer for Enhanced Oil Recovery Technology " Procedia Chemistry, 2012.

[60] Sorbie KS, "Polymer-improved oil recovery.Glasgow," Blackie and Son Ltd,, 1991.

[61] B. J. Chatterji J, "Applications of watersoluble polymers in the oil field.," J Pet Technol, vol. 33:2,042-042,056, 1981.

[62] W. Y. Chen Q., Lu Z., Feng Y., "Thermoviscosifying Polymer Used for Enhanced Oil Recovery: Rheological Behaviors and Core Flooding Test," Polym. Bull., vol. 70:391-40, 2013.

[63] Nabih K. R., "Geotechnical Applications of Biopolymer Technology,," Civil Engineering, USC Doctor of Philisophy dissertation, USC, 2001.

[64] L. Y. Sang Q., Li Z., Dong M., "Enhanced Oil Recovery by Branched-Preformed Particle Gel Injection in Parallel-Sandpack Models," Fuel vol. 136 (2014) 295-306, 2014.

[65] Sheng J., "Modern Chemical Enhanced Oil Recovery-Theory and Practice," 2011.

[66] S. R. S. Liang J., "Further Investigations of Why Gels Reduce Water Permeability More Than Oil Permeability,", SPE Production and Facilities, 1997.

[67] B. B. Tongwa P., "Degradable Nanocomposite Preformed Particle Gel for Chemical Enhanced Oil Recovery Applications, ," Journal of Petroleum Science and Engineering vol. 124 (2014) 35-45, 2014.

[68] S. M. M. Sameer Al-Hajri, Hesham Abdulelah and Saeed Akbari, "An Overview on Polymer Retention in Porous Media," energies, 2018.

[69] W. Z. Huiying Zhong, Jing Fu, Jun Lu and Hongjun Yin "The Performance of Polymer Flooding in Heterogeneous Type II Reservoirs-An Experimental and Field Investigation," energies, 2017.

[70] P. D. J.J.S., "Modern Chemical Enhanced Oil Recovery Theory and Practice, 2011.," 2011.

[71] R. S. Seright, "Disproportionate permeability reduction with pore-filling gels. SPE, 2009. ," SPE, vol. PP.5-13., 2009 